\title{
Transport of Nutrients and Hormones through the Blood-Brain Barrier
}

\author{
W. M. Pardridge \\ Department of Medicine, Division of Endocrinology and Metabolism, UCLA School of Medicine, Los Angeles, California, USA
}

\begin{abstract}
Summary. An understanding of the mechanisms of transport of circulating nutrients and hormones through the brain capillary wall, i. e., the blood-brain barrier, is important because the availability in brain of these substances influences a number of cerebral metabolic pathways. For example, the utilization by brain of glucose, ketone bodies and branched chain amino acids or the production of monoamines, acetylcholine, carnosine, and nucleosides may under certain conditions be influenced by BBB transport of circulating precursor nutrients. Steroid and thyroid hormones readily traverse the $\mathrm{BBB}$ via lipid-mediation and carrier-mediation, respectively. Although the steroid and thyroid hormones are tightly bound by plasma proteins, protein-bound hormone, not the free (dialyzable) moiety, is the major plasma fraction transported through the BBB. With regard to circulating peptides, the available evidence indicates peptides rapidly distribute into brain interstitial space of the circumventricular organs of brain, i. e., about six small regions around the ventricles which lack a BBB. Conversely, the absence of peptide carriers in the BBB prevents the rapid distribution of peptides into the vast majority of brain interstitial or synaptic spaces. However, recent studies indicate that some peptides, e. g., insulin, may bind specific receptors on the blood side of the BBB and thereby transmit messages to cells on the brain side of the $\mathrm{BBB}$, without the peptide traversing the capillary wall.
\end{abstract}

Key words: Blood-brain barrier, brain metabolism, steroid hormones, thyroid hormones, peptides

The capillaries of virtually all vertebrate brains are characterized by unique anatomical features [1]. The adjacent endothelia of cerebral capillaries are tightly fused together by high resistance, epithelial-like tight junctions. In addition, brain capillaries have a paucity of pinocytosis and few, if any, fenestrations. These structural features comprise the anatomical basis of the blood-brain barrier (BBB), the permeability properties of which are determined by the endothelial plasma membranes. The cerebral capillary endothelia plasmalemma is effectively the cell membrane of the entire brain with regional specializations. The presence of the $\mathrm{BBB}$ prevents circulating water-soluble substances from rapidly distributing, via free diffusion, into brain interstitial or synaptic spaces. Only two routes of penetration into brain are available for blood-borne substances: (i) lipid-mediation, in the case of lipid-soluble compounds such as steroid hormones [2], melatonin [3], or free fatty acid [4], or (ii) carrier-mediation, in the case of watersoluble compounds which have an affinity for one of nine specific transport systems located in the BBB (Table 1). This chapter will review the basic mechanisms by which nutrients or hormones traverse the BBB by either carrier- or lipid-mediation. In the case of nutrient transport, special emphasis will be placed on the regulatory role of $\mathrm{BBB}$ transport in the control of substrate-limited pathways of cerebral metabolism. With regard to hormone transport, the rapid transport through the $\mathrm{BBB}$ of protein-bound steroid and thyroid hormones will be emphasized. Finally, the role of the BBB in regard to circulating neuropeptides will be discussed and the hypothesis will be advanced that peptides do not cross the BBB, but may bind and activate specific receptors on the luminal aspect of cerebral endothelia.

\section{Nutrient Transport}

The importance of carrier-mediated transport of essential nutrients (e.g., glucose, ketone bodies, amino acids, choline, purine bases and nucelosides) 
at the $\mathrm{BBB}$ becomes apparent when one recognizes that not all pathways of brain metabolism are ratecontrolled by the catalytic activity $\left(\mathrm{K}_{\mathrm{m}}, \mathrm{V}_{\max }\right)$ of intracellular enzymes. Rather many, if not most, pathways of cerebral metabolism can be influenced by the availability of blood-borne substrate made available to rate-limiting enzymes. The availability of essential substrates in brain is controlled by both plasma levels of the substrate [9] and the activity $\left(\mathrm{K}_{\mathrm{m}}\right.$, $\mathrm{V}_{\mathrm{max}}$ ) of BBB transport systems. The nutrient transport systems (Table 1) have been discussed in detail in previous reviews $[5,7,10]$. The pathways mediating the metabolism of these nutrients are classified in Table 2 according to whether the pathway is substrate-limited (transport-dependent) or enzymelimited (transport-independent).

There are two types of substrate-limited pathways (Table 2). If the slow step in the pathway is $\mathrm{BBB}$ transport, then the pathway is transportlimited; these pathways are easily identified experimentally, e. g., the intracellular precursor concentration is immeasureably low. Examples of transportlimited pathways of brain metabolism are ketone

Table 1. Blood-brain barrier transport systems

\begin{tabular}{lllc}
\hline Transport system & $\begin{array}{l}\text { Representative } \\
\text { substrate }\end{array}$ & $\begin{array}{l}\mathrm{K}_{\mathrm{m}} \\
(\mathrm{mM})\end{array}$ & $\begin{array}{l}\mathrm{V}_{\text {max }} \\
(\mathrm{nmol} \\
\left.\mathrm{min}^{-1} \mathrm{~g}^{-1}\right)\end{array}$ \\
\hline Hexose & Glucose & 9 & 1600 \\
Monocarboxylic acid & Lactate & 1.9 & 120 \\
Neutral amino acid & Phenylalanine & 0.12 & 30 \\
Amine & Choline & 0.44 & 10 \\
Basic amino acid & Lysine & 0.10 & 6 \\
Purine & Adenine & 0.027 & 1 \\
Nucleoside & Adenosine & 0.018 & 0.7 \\
Acidic amino acid & Glutamate & 0.04 & 0.4 \\
Thyroid hormone & $\mathrm{T}_{3}$ & 0.001 & 0.1 \\
\hline
\end{tabular}

From (5-8) body utilization under physiologic conditions of ketosis (e.g., fasting, high fat diet, neonatal period) or glycolysis under abnormal conditions (e.g., hypoglycemia). Unlike muscle, where the rate-limiting step in ketone body utilization is the acetoacetatesuccinyl CoA transferase [12], the rate-limiting step of ketone body utilization in brain is the $\mathrm{BBB}$ transport step [13]. Moreover, the activity of the $\mathrm{BBB}$ lactate/ketone body transport system is greatly induced in states of ketosis $[14,15]$. The divergent modes of metabolic regulation among brain and muscle is also true for glucose metabolism. In skeletal muscle, intracellular glucose is normally near zero [16], indicating muscle glucose utilization is limited by the cell membrane transport step. Conversely, brain glucose is normally measureable, which indicates glucose phosphorylation in brain is limited by hexokinase; since hexokinase $\left(\mathrm{K}_{\mathrm{m}}=40 \mathrm{uM}\right)$ is normally well saturated by glucose, glycolysis in brain normally proceeds at rates completely independent of changes in either plasma glucose or the BBB hexose carrier. However, it is not often appreciated that under pathologic conditions cerebral glycolysis may be limited by BBB transport of glucose. One obvious cause of transport-limitation of cerebral glycolysis is hypoglycemia. For example, when plasma glucose in the rat falls below $50 \mathrm{mg} \%$, intracellular glucose is immeasureably low [17]. Less obvious causes of transport-limitation are cases of "relative hypoglycemia," e.g., wherein sugar influx into brain proceeds at normal rates, but owing to pathologic elevations in rates of brain glycolysis, sugar supply via transport does not keep pace with increased demand via glycolysis. Under these conditions, e. g., anoxiaischemia [18], seizures [19], or salicylate intoxication [20], brain glucose may fall to zero and the overall rate of cerebral glycolysis becomes limited by the kinetics of $\mathrm{BBB}$ glucose transport. Moreover, it is probable that "relative hypoglycemia" may manifest

Table 2. Classification of pathways of brain metabolism

\begin{tabular}{|c|c|c|c|c|}
\hline Category & Rate-limiting step & $\begin{array}{l}\text { Substrate: } K_{m} \text { rela- } \\
\text { tionship }\end{array}$ & $\begin{array}{l}\text { Intracellular sub- } \\
\text { strate concentration }\end{array}$ & Example pathways \\
\hline \multirow[t]{2}{*}{ Substrate-dependent } & BBB-transport & $\mathrm{S}_{\mathrm{p}} \leq \mathrm{K}_{\mathrm{m} \mathrm{r}}$ & Low & $\begin{array}{l}\text { Glycolysis (abnormal states); } \\
\text { ketone body utilization }\end{array}$ \\
\hline & Intracellular enzyme & $\mathrm{S}_{\mathrm{IC}} \leq \mathrm{K}_{\mathrm{mE}}$ & High & $\begin{array}{l}\text { Monamine, acetylcholine syn- } \\
\text { thesis; S-adenosyl methionine syn- } \\
\text { thesis; leucine oxidation; protein } \\
\text { synthesis (abnormal states) }\end{array}$ \\
\hline Substrate-independent & Intracellular enzyme & $\mathrm{S}_{\mathrm{IC}}>\mathrm{K}_{\mathrm{mE}}$ & High & $\begin{array}{l}\text { Glycolysis; protein synthesis (nor- } \\
\text { mal states) }\end{array}$ \\
\hline
\end{tabular}

From [5, 11]

Abbreviations used: $S_{p}$, substrate plasma level; $K_{m T}, K_{m}$ of transport step; $S_{\mathrm{IC}}$, substrate intracellular concentration; $K_{m E}, K_{m}$ of enzymatic step 
on a regional basis, wherein, owing to increased regional energy demand, sugar transport through the BBB may become rate-limiting for a particular region. Insight into the phenomenon that brain glycolysis may, under certain conditions, switch from phosphorylation-limitation (substrate-independency) to transport-limitation (substrate-dependency) is essential, since methods are now available to routinely study regional cerebral glycolysis in man [21].

The second major class of substrate-limited pathways in brain are those limited not by BBB transport, but by an intracellular enzyme. However, owing to an intracellular precursor concentration less than or equal to the $\mathrm{K}_{\mathrm{m}}$ of the rate-limiting enzyme, then BBB transport, by controlling precursor availability, may still be a rate-affecting step in the pathway [5]. Examples of such pathways are routes of amino acid metabolism. For example, the following putative neurotransmitter compounds, serotonin, catecholamines, histamine, and carnosine, are synthesized from tryptophan, tyrosine, and histidine, respectively, via substrate-dependent reactions [22, 23, 24]. In addition, the rate of synthesis of S-adenosyl methionine [25], the oxidation of branched chain amino acids [26], or the production of acetylcholine [27] is, respectively, influenced by the availability of methionine, branched chain amino acids, or choline. Another important pathway of brain amino acid metabolism is protein synthesis. Protein synthesis in tissues of the CNS becomes half-saturated at about $10 \mathrm{uM}$ amino acid [28], a concentration which is less than $10 \%$ of amino acid pools in brain; therefore, cerebral protein synthesis is normally independent of amino acid availability. However, if amino acid pools in brain are contracted due to decreased BBB transport of essential amino acids, e.g., as occurs with selective hyperaminoacidemias, then brain protein synthesis may become substrate-limited.

Another pathway of brain metabolism which may be substrate-limited is the salvage by brain of circulating purine bases. The recognition that brain cannot synthesize purine bases at rates sufficient to meet tissue demand for the compounds means that purine bases should be regarded as essential nutrients to the brain (see [5]). In peripheral tissues, the conversion of extracellular nucleoside is limited by cell membrane transport of the bases [29]. Whether a similar transport-limitation occurs in brain for purine base utilization is not known at present, due principally to the critical lack of information on brain purine base levels. Purine nucleosides, e.g., adenosine, exist in brain at a concentration of about $1 \mathrm{uM}$ [30], which approximates plasma adenosine levels [31], but data on purine base levels obtained with the requisite highly sensitive methods needed for resolution and quantitation are thus far apparently not reported. One indirect observation which indicates the developing brain is critically dependent on the supply of purine bases is the fact that the rate of adenine transport through the newborn rabbit $\mathrm{BBB}$ is about 10 -fold faster than transport in the adult animal [32].

\section{Modulations of BBB Nutrient Transport}

Given the many pathways of brain metabolism that are subject to substrate-limitation (Table 2), information on the modulations of BBB transport phenomena is critical to an understanding of the regulation of brain metabolism under normal or pathologic conditions. Perhaps the most dramatic example of widespread modulation of barrier transport systems is the newborn period [32]. While it is often stated that the newborn BBB is less developed than in the adult, the BBB of the newborn is actually a highly developed membrane system. The endothelial tight junctions, i. e., the anatomical basis of the $\mathrm{BBB}$, are already formed by the first trimester of human fetal life [33]. Moreover, in the newborn rabbit brain, there are striking increases in the activity of three BBB transport systems: the choline carrier, the purine base system, and the basic amino acid carrier are all much more active relative to the adult [32]. Basic amino acids (arginine, lysine) are generally regarded as essential nutrients and, as such, are administered to ill newborn patients. However, such compounds as choline or adenine are not generally regarded as essential dietary nutrients needed by the developing brain and, consequently, are not usually administered via parenteral nutrition to newborns. However, the dramatic increases in $\mathrm{BBB}$ transport of choline or adenine in the newborn is compelling evidence that the developing brain requires choline and adenine in increased amounts. Moreover, ornithine, a non-essential amino acid and a precursor to polyamines, is not regarded as an essential nutrient for brain. However, the dramatic increase in BBB basic amino acid transport in the newborn may represent an adaptation by brain to increase cerebral ornithine supply, apart from the internal conversion of brain arginine to ornithine.

Another example of diet-related modulations of a BBB transport system is the induction of the monocarboxylic acid carrier (Table 1), which occurs under states of ketosis, e. g., the suckling period, fasting, or high fat diets $[14,15]$. Moreover, since ketone body utilization is limited by BBB transport [13], the degree to which the carrier is induced sets the overall pace of ketone body utilization. Moreover, recent autoradiographic studies by Hawkins and coworkers 
[13], indicate the presence of a marked regional specificity to BBB transport and brain utilization of ketone bodies. For example, lower cortical areas selectively consume $\beta$-hydroxybutyrate relative to upper cortical regions.

An example of modulation of a BBB transport system under pathologic conditions is the induction of the neutral amino acid carrier which occurs in hepatic encephalopathy [34]. James, Fischer, and associates [35], have suggested a provocative hypothesis which may explain the mechanism of the induction process. Brain ammonia is increased in hepatic encephalogpathy and, consequently, the level of brain glutamine is elevated. Glutamine is a neutral, non-essential amino acid, which has only a modest affinity for the BBB neutral amino acid carrier [36]. However, glutamine is unique among the amino acids in that the CSF level and presumably the interstitial concentration is nearly equal to the plasma glutamine level [37]. Conversely, the CSF level of other amino acids is only $10-15 \%$ or less of the corresponding plasma level [37]. Consequently, the majority of $\mathrm{BBB}$ neutral amino acid transport sites on the brain side of the $\mathrm{BBB}$ are occupied by glutamine. The neutral amino acid system demonstrates exchange diffusion [38], i. e., when the carrier is loaded with substrate, e.g., glutamine, it moves through the BBB faster than unloaded carrier [39]. The enhanced carrier mobility through the membrane is reflected by an increased $V_{\max }$ [34]. James et al. [35] have observed an increase in $V_{\max }$ in parallel to ammonia-induced increases in brain glutamine. Moreover, the glutamine-induced acceleration of the activity of the BBB neutral amino acid carrier results in enhanced influx into brain of circulating neutral amino acids. Since tryptophan, tyrosine, and histidine are neutral amino acid precursors to putative neurotransmitters, the rate of glutamine production and efflux from brain may be ultimately linked to monoamine production via glutamine induction of the BBB neutral amino acid carrier [35].

\section{Steroid and Thyroid Hormone Transport}

The impact of steroid or thyroid hormone availability in brain is best demonstrated by the striking encephalopathy associated with corticosteroid or thyroid hormone deficiency or excess [40, 41]. Moreover, the supply in the developing brain of gonadal steroid is believed to be linked to the development of sexually dimorphic behaviors [42]. Since the steroid hormones enter brain via lipidmediation, i. e., free diffusion [2], and the thyroid hormones traverse the BBB by a carrier system with a $\mathrm{K}_{\mathrm{m}}$ that is high relative to thyronine plasma levels [8], the supply in brain of these hormones is a function of the existing plasma concentration. The interpretation of plasma levels of steroid or thyroid hormone is complicated by the active protein binding of these substances. The problem of protein binding effects has generally been resolved by the somewhat simplistic view that the fraction of hormone that is free, non-protein bound, in vitro at equilibrium is equal to the fraction of hormone that is free in vivo, e. g., at the brain capillary. Therefore, the free hormone in vivo may be measured by simply multiplying the total hormone level by the free, e. g., dialyzable, fraction in vitro. Certainly, no one would argue that the dynamics of hormone flux through the $\mathrm{BBB}$, or through any cell membrane, may be more intricate than processes which occur in a test tube. In fact, hormone transport in vivo is a function of three parameters which are not measured by in vitro studies at equilibrium. These parameters are: (i) the capillary tansit time, e.g., 1-5 sec, (ii) the unidirectional rate of hormone debinding from the protein, e. g., msec to sec, and (iii) the half-time of hormone flux through a biological membrane, e. g., msec to sec, for the steroid or thyroid hormones $[2,8]$. That is, the free fraction of hormone in vivo is a time- and permeability-dependent parameter. Therefore, for a tissue such as liver, wherein the capillary transit time is longer and, owing to the extensive surface area of the hepatocyte cell membrane, the permeability is greater, the free fraction of hormone in liver may be greater than that in brain capillaries [43, 44]. The free fraction of hormone in both brain and liver thas been measured for a number of steroid and thyroid hormones. These results are summarized in Table 3. Briefly, on the basis of these studies, the following generalizations may be reached. (i) The free (dialyzable) fraction of hormone is trivial compared to the large protein-bound moiety that is available for transport into brain. (ii) Albumin-bound hormone is readily transported into tissues. (iii) Hormones bound to such globulins as TBG, SHGB, or CBG (Table 3) are not transported into a tissue such as brain but TBG-bound $\mathrm{T}_{3}$, SHGB-bound estradiol, or CBG-bound corticosteroid is readily transported into liver; therefore, the function of the binding globulin may be to amplify the amount of hormone available to the metabolically active liver, relative to peripheral tissues such as brain.

\section{Peptides and the Blood-Brain Barrier}

Peptides are water-soluble substances and, consequently, are not able to rapidly traverse the $\mathrm{BBB}$ via lipid-mediation. Moreover, specific peptide transport 
Table 3. Transport of protein-bound substances through the blood-brain barrier vs the liver cell membrane

\begin{tabular}{llll}
\hline Hormone & Plasma protein & $\begin{array}{l}\text { BBB } \\
\text { transport }\end{array}$ & $\begin{array}{l}\text { Liver cell } \\
\text { transport }\end{array}$ \\
\hline $\mathrm{T}_{3}$ & Albumin & + & + \\
$\mathrm{T}_{4}$ & TBG & - & + \\
& Albumin & + & + \\
Testosterone & TBPA & - & - \\
& TBG & - & - \\
Estradiol & Albumin & + & + \\
& SHBG & - & - \\
Corticosteroid & PBG & + & ND \\
& Albumin & + & + \\
Progesterone & Albumin & - & + \\
& CBG & + & ND \\
& Albumin & + & + \\
& PBG & + & + \\
Melatonin & Specific rabbit & & + \\
Free fatty acid & antiserum & - & ND \\
Cholesterol & Albumin & + & + \\
& Llbumin & + & + \\
& Lipoprotein & - & ND
\end{tabular}

From $(2,3,4,8,43,44,45)$

Abbreviations used: TBG, thyroid binding globulin; TBPA, thyroid binding prealbumin; SHBG, sex hormone binding globulin; PBG, progesterone binding globulin; EBP, estradiol binding protein of neonatal rat serum; CBG, corticosteroid binding globulin, ND, not determined

systems have not been heretofore shown to function at the BBB [46]. For example, enkephalin transport through the $\mathrm{BBB}$ is characterized by a slow, nonsaturable rate of flux that is on the order of magnitude of other putative neurotransmitter substances which also exist in the plasma [46]. Although a recent report suggests enkephalins are readily transported through the BBB [47], a re-evaluation of these data confirms the original report of a low BBB permeability to enkephalins [48].

Insulin is another peptide which has been shown to not cross the BBB [49]. However, the CSF/plasma ratio of insulin is about $25 \%$ [50] or approximately 10 -fold the CSF/plasma ratio for inulin [51], an extracellular space marker of comparable molecular weight (mw 5000) as insulin. The high CSF/plasma ratio for insulin indicates the peptide is selectively transported into brain. This latter suggestion is not in contradiction to the observation that insulin does not cross the BBB. About $0.5 \%$ of the brain capillary surface area perfuses the circumventricular organs (CVO) of brain (see [48]), e. g., the median eminence, the organum vasculosum of the lamina terminalis, the subfornical organ, the subcommissural organ, the area postrema, and the choroid plexus. With the exception of the subcommissural organ, the CVO's are characterized by an absence of the BBB [52].Therefore, circulating substances, e. g., peptides, readily gain access to brain interstitial fluid in the CVO's and then may be selectively transported into ventricular CSF by specific ependymal transport mechanisms.

In addition to providing a mechanism by which peptides may gain access to ependymal transport systems, the CVO's may also, by virtue of the absence of the $\mathrm{BBB}$, provide a mechanism by which circulating peptides may come in direct contact with neuronal elements. Elegant studies recently reported by Van Houten, Posner and associates [53] have documented the presence of specific, saturable insulin receptors in nerve terminals of the median eminence and its contigious region, the arcuate nucleus.

The previous discussion has emphasized the view that peptides may slowly gain access to brain by selective transport through the ependyma of the CVO's or may rapidly gain access to neuronal elements within or contigious with the CVO's. Conversely, the rapid distribution of circulating peptides into brain interstitial or synaptic spaces is prevented by the absence of specific transport systems in the BBB. However, it may still be possible for circulating peptides to rapidly transmit signals to cells on the brain side of the $\mathrm{BBB}$ given the presence of peptide receptors on the blood side of the BBB. In fact, Van Houten and Posner [54] have recently documented the presence of saturable insulin receptors on the endothelia of brain capillaries. Moreover, direct in vitro evidence for specific insulin receptors on brain capillaries has recently been obtained with a BBB radio-receptor assay; $\left({ }^{125} \mathrm{I}\right)$ insulin binds to isolated cerebral microvessels by a saturable process that is $50 \%$ inhibited by $1 \mathrm{nM}$ insulin, but which is not saturated by large doses of other peptides such as prolactin, thyrotropin, or growth hormone [48].

In addition to characterizing the $\mathrm{BBB}$ receptor for insulin (and receptors for other peptides), the isolated brain capillary [55] may prove to be a useful preparation for elucidating the second messenger(s) released to brain interstitial space by insulin binding to the endothelial receptor. Such putative second messengers may then mediate insulin action on the brain. Although insulin is known not to stimulate transport of either glucose [56] or potassium into brain $[55,57]$, insulin does increase cerebral glycogen synthesis [58].

Acknowledgements. Studies in the author's laboratory are supported by NIH grant AM-25744, National Science Foundation grant BNS 78-05500, a Basil O'Connor grant from the National 
Foundation-March of Dimes, and NIH Clinical Investigator Award AM-00409. The author is indebted to Larry Mietus for outstanding technical assistance and to Charlotte Limberg for preparing the manuscript.

\section{References}

1. Brightman MW (1975) Morphology of blood-brain interfaces. In: Bito LZ, Davson H, Fenstermacher JD (eds) The ocular and cerebrospinal fluids, pl-25. NIH, Bethesda Maryland

2. Pardridge WM, Mietus LJ (1979) Transport of steroid hormones through the rat blood-brain barrier. J Clin Invest 64 : 145-154

3. Pardridge WM, Mietus LJ (1980) Transport of albumin-bound melatonin through the blood-brain barrier. J Neurochem 34 : 1761-1763

4. Pardridge WM, Mietus LJ (1980) Palmitate and cholesterol transport through the blood-brain barrier. J Neurochem 34: 463-466

5. Pardridge WM, Oldendorf WH (1977) Transport of metabolic substrates through the blood-brain barrier. J Neurochem 28: $5-12$

6. Cornford EM, Braun LD, Oldendorf WH (1978) Carrier mediated blood-brain barrier transport of choline and certain choline analogs. J Neurochem 30: 299-308

7. Pardridge WM (1979) Regulation of amino acid availability to brain: Selective control mechanisms for glutamate. In: Filer $\mathbf{J}_{\mathbf{r}}$ LF, et al (eds) Advances in biochemistry and physiology, Raven Press, New York, p 125-137

8. Pardridge WM (1979) Carrier-mediated transport of thyroid hormones through the rat blood-brain barrier: Primary role of albumin-bound hormone. Endocrinology 105: 605-612

9. Wurtman RJ, Fernstrom JD (1975) Control of brain monoamine synthesis by diet and plasma amino acids. Am J Clin Nutr 28: 638-647

10. Pardridge WM, Cornford EM, Braun LD, Oldendorf WH (1979) Transport of choline and choline analogues through the blood-brain barrier. In: Barbeau A, Growdon JH, Wurtman RJ (eds) Nutrition and brain, vol. 5, Raven Press, New York, pp 25-33

11. Pardridge WM (1979) The role of blood-brain barrier transport of tryptophan and other neutral amino acids in the regulation of substrate-limited pathways of brain metabolism. In: Baumann P (ed) Transport mechanisms of tryptophan in blood cells, nerve cells, and at the blood-brain barrier, p 43-54. Springer, Berlin Heidelberg New York

12. Owen OE, Markus H, Barshik S, Mozzoli M (1973) Relationship between plasma and muscle concentrations of ketone bodies and free fatty acids in fed, starved and alloxan-diabetic states. Biochem J 134: 499-506

13. Hawkins RA, Biebuyck JP (1979) Ketone bodies are selectively used by individual brain regions. Science 205: 325-327

14. Gjedde A, Crone C (1975) Induction processes in blood-brain transfer of ketone bodies during starvation. Am J Physiol 229: 1165-1169

15. Moore TJ, Lione AP, Sugden MC, Regen DM (1976) $\beta$-Hydroxybutyrate transport in rat brain: developmental and dietary modulations. Am J Physiol 230: 619-630

16. Kipnis DM, Helmreich E, Cori CF (1959) Studies of tissue permeability. IV. The distribution of glucose between plasma and muscle. J Biol Chem 234: 165-170

17. Lewis LD, Ljunggren B, Norberg K, Siesjo BK (1974) Changes in carbohydrate substrates, amino acids and ammonia in the brain during insulin-induced hypoglycemia. $J$ Neurochem 23: 659-671
18. Betz AL, Gilboe DD, Drewes LR (1974) Effects of anoxia on net uptake and unidirectional transport of glucose into the isolated dog brain. Brain Res 67: 307-316

19. Chapman AG, Meldrum BS, Siesjo BK (1977) Cerebral metabolic changes during prolonged epileptic seizures in rats. $\mathrm{J}$ Neurochem 28: 1025-1035

20. Thurston JH, Pollock PG, Warren SK, Jones EM (1970) Reduced brain glucose with normal plasma glucose in salicylate poisoning. $\mathrm{J}$ Clin Invest $49: 2139-2145$

21. Phelps ME, Huang SC, Hoffman EJ, Selin C, Sokoloff L, Kuhl DE (1979) Tomographic measurement of local cerebral glucose metabolic rate in humans with (F-18) 2-fluoro-2-deoxyD-glucose: Validation of method. Ann Neurol 6: 371-388

22. Fernstrom JD, Wurtman RJ (1971) Brain serotonin content: physiological dependence on plasma tryptophan levels. Science 173: 149-151

23. Gibson CJ, Wurtman RJ (1978) Physiological control of brain norepinephrine synthesis by brain tyrosine concentration. Life Sci 22: 1399-1406

24. Taylor KM, Snyder SH (1972) Dynamics of the regulation of histamine levels in mouse brain. J Neurochem 19: 341-354

25. Rubin RA, Ordonez LA, Wurtman RJ (1974) Physiological dependence of brain methionine and S-adenosylmethionine concentrations on serum amino acid pattern. J Neurochem 23: 227-231

26. Chaplin ER, Goldberg AL, Diamond I (1976) Leucine oxidation in brain slices and nerve endings. $J$ Neurochem 26: 701-707

27. Cohen EL, Wurtman RJ (1976) Brain acetylcholine: Control by dietary choline. Science 191: 561-562

28. Ames III A, Parks JM (1976) Functional homogeneity of leucine pool in retina cells. J Neurochem 27: 1017-1025

29. Marz R, Wohlhueter RM, Plagemann PGW (1979) Purine and pyrimidine transport and phosphoribosylation and their interaction in overall uptake by cultured mammalian cells. A re-evaluation. J Biol Chem 254: 2329-2338

30. Nordstrom $\mathrm{CH}$, Rehncrona $\mathrm{S}$, Siesjo BK, Westerberg E (1977) Adenosine in rat cerebral cortex: Its determination, normal values, and correlation to AMP and cyclic AMP during shortlasting ischemia. Acta Physiol Scand 101: 63-71

31. Pritchard JB, O'Connor N, Oliver JM, Berlin RD (1975) Uptake and supply of purine compounds by the liver. Am J Physiol 229: 967-972

32. Braun LD, Cornford EM, Oldendorf WH (1980) Newborn rabbit blood-brain barrier is selectively permeable and differs substantially from the adult. J Neurochem 34: 147-152

33. Møllgard K, Saunders NR (1975) Complex tight junctions of epithelial and of endothelial cells in early foetal brain. $J$ Neurocytol 4: 453-568

34. James JH, Escourrou J, Fischer JE (1978) Blood-brain neutral amino acid transport activity is increased after portacaval anastomosis. Science 200: 1395-1397

35. James JH, Jeppsson B, Ziparo V, Fischer JE (1979) Hyperammonaemia, plasma aminoacid imbalance, and blood-brain aminoacid transport: a unified theory of portal-systemic encephalopathy. Lancet II: 772-775

36. Oldendorf WH (1971) Brain uptake of radiolabeled amino acids, amines, and hexoses after arterial injection. Am J Physiol 221: 1629-1639

37. Perry TL, Hansen S, Kennedy J (1975) CSF amino acids and plasma - CSF amino acid ratios in adults. $J$ Neurochem 24: $587-589$

38. Toth J Lajtha A (1977) Rates of exchange of free amino acids between plasma and brain in mice. Neurochem Res 2: $149-160$

39. Betz AL, Gilboe DD, Drewes LR (1975) Accelerative exchange diffusion kinetics of glucose between blood and 
brain and its relation to transport during anoxia. Biochim Biophys Acta 401: 416-428

40. Gold EM (1979) The Cushing syndromes: Changing views of diagnosis and treatment. Ann Intern Med 90: 829-844

41. Sanders V (1962) Neurologic manifestations of myxedema. N Engl J Med 266: 547-552

42. Gorski RA (1973) Perinatal effects of sex steroids on brain development and function. Prog Brain Res 39: 149-163

43. Pardridge WM, Mietus LJ (1980) Influx of thyroid hormones into rat liver in vivo. Primary role of protein-bound hormone. J Clin Invest 66: 367-374

44. Pardridge WM, Mietus LJ (1979) Transport of protein-bound steroid hormones into liver in vivo. Am J Physiol 237: E367-E372

45. Pardridge WM, Mietus LJ (1980) Effects of progesteronebinding globulin versus a progesterone antiserum on steroid hormone transport through the blood-brain barrier. Endocrinology 106: 1137-1141

46. Cornford EM, Braun LD, Crane PD, Oldendorf WH (1978) Blood-brain barrier restriction of peptides and the low uptake of enkephalins. Endocrinology 103: 1297-1303

47. Rapoport SI, Klee WA, Pettigrew KD, Ohno K (1980) Entry of opioid peptides into the central nervous system. Science 207: 84-86

48. Pardridge WM, Frank HJL, Cornford EM, Braun LD, Crane PD, Oldendorf WH (1981) Neuropeptides and the bloodbrain barrier. In: Martin JB, et al. (eds) Neurosecretion and brain peptides. Raven Press, New York, p 321-328

49. Groodner CJ, Berrie MA (1977) The failure of rat hypothalamic tissues to take up labeled insulin in vivo or to respond to insulin in vitro. Endocrinology 101: 605-612

50. Woods SC, Porte Jr D (1977) Relationship between plasma and cerebrospinal fluid insulin levels of dogs. Am J Physiol 233: E331-E334

\section{Discussion after Pardridge's Presentation}

Fernstrom: If glutamate is indeed transported out of brain by the transport system working in reverse, then aspartate and glycine should logically be extruded as well. Perhaps it is the case that the CNS gets rid of all of its amino acid neurotransmitters by this method; or perhaps it is simply a mechanism that allows for metabolites to be pumped out.

Pardridge: All of these are possible.

Fernstrom: Is it possible that separate selective transport systems exist for expelling compounds from the brain? or is it a bidirectional system?

Pardridge: If it's a bidirectional transport system, the permeability on the brain side has got to be the same as the permeability on the blood side. You couldn't get glutamate out any faster than the blood-side permeability would permit. And since we know the permeability of glutamate on the blood side, one couldn't explain the rapid expulsion you suggest. There would have to be an asymmetry if it is being produced that fast and getting out. There would have to be a specific mechanism for getting it out.

Fernstrom: When PRL is given IVT, it causes a decrease of PRL secretion. Does PRL get into the CNS via the CSF? or into the anterior pituitary? or how might it normally cause this effect?
51. Dziegielewska KM, Evans CAN, Malinowska DH, Møligard K, Reynolds JM, Reynolds ML, Saunders NR (1979) Studies of the development of brain barrier systems to lipid insoluble molecules in fetal sheep. J Physiol (Lond) 292: 207-231

52. Weindl A (1973) Neuroendocrine aspects of circumventricular organs. In: Ganong WF, Martini L (eds) Frontiers in neuroendocrinology, Oxford University Press, New York, p 3-32

53. Van Houten M, Posner BI, Kopriwa BM, Brawer JR (1980) Insulin binding sites localized to nerve terminals in rat median eminence and arcuate nucleus. Science 207: 1081-1083

54. Van Houten M, Posner BI (1979) Insulin binds to brain blood vessels in vivo. Nature 282: 623-625

55. Goldstein GW (1979) Relation of potassium transport to oxidative metabolism in isolated brain capillaries. J Physiol (Lond) 286: 185-195

56. Betz AL, Gilboe DD, Yudilevich DL, Drewes LR (1973) Kinetics of unidirectional glucose transport into the isolated dog brain. Am J Physiol 225: 586-592

57. Thurston JH, Hauhart RE, Dirgo JA, McDougal Jr DB (1977) Insulin and brain metabolism. Absence of direct action of insulin on $\mathrm{K}^{+}$and $\mathrm{Na}^{+}$transport in normal rabbit brain. Diabetes 26: $1117-1119$

58. Daniel PM, Love ER, Pratt OE (1977) The influence of insulin upon the metabolism of glucose by the brain. Proc R Soc Lond [Biol] 196: 85-104

Dr. William M. Pardridge

Department of Medicine/Endocrinology

UCLA School of Medicine

Los Angeles, CA 90024

USA

Pardridge: It is unlikely to enter at the anterior pituitary, so it must get in elsewhere. It is a much smaller molecule than HRP so it would have no trouble entering at the median eminence from the blood. From the CSF, it could not get into the median eminence unless that area has a specific transport system for PRL, and this has never been reported. It might also get there very slowly by entering adjacent brain areas where there is no CSF-brain barrier and then backtracking into the median eminence.

Fernstrom: You speak highly of the Oldendorf technique, but isn't it actually limited because it uses whole brain rather than specific brain areas?

Pardridge: That has been true in the past, but the method can easily be adapted to study specific brain areas. One would simply inject a greater amount of specific activity into the carotid and then use the Palkovitz technique to punch out areas of interest.

Fernstrom: Can one get around the problem of blood brain barrier permeability by having some kind of tag attached to a molecule?

Pardridge: The phenomenon you suggest is called latentiation. The classic example of it is the potentiation of morphine entry into the brain by the addition of certain side 
chains such that the molecule is converted to heroin. Heroin is two log orders more permeable through the $\mathrm{BBB}$ than morphine because the latter has two hydroxyl groups (Science (1972) 178: 984). Each hydroxyl group lowers BBB permeability by a log order. But you can mask those by the addition of two acetyl groups and thereby increase the permeability by those same two log orders. Heroin is therefore a vehicle for getting the morphine molecule into the brain. So instead of a first-pass extraction of $1 \%$, you get $60 \%$. Once the molecule gets into the brain, capillary pseudo-cholinesterase causes its reconversion to morphine. The same thing could be done to block polar groups on peptides; i. e., to add apolar groups such as acetyl groups. These could then be cleaved once the peptide achieved distribution within the brain. This could all be done in a good pharmacology lab.

B. Jeanrenaud: Are there selective inhibitors for selective transport systems?

Pardridge: Yes, for example, when you administer 2-deoxyglucose (2-DG), yet get a kind of hypoglycemic reaction. If you can achieve a 2-DG level of $100 \mathrm{mg} \%$, it will saturate the glucose transport carrier site and essentially starve the brain of glucose. The neutral amino acid transport system could be blocked with cyclo-leucine, a nonmetabolizable analog. There are no good inhibitors of the monocarboxylic acid clactate-ketonebody system. Alphacyano-hydroxycinnamic acid could possibly be an inhibitor of the ketone body transport system. There's no good nonmetabolizable amino acid analog for the basic amino acid transport system. Caffeine is a purine-like compound which may be an inhibitor of the purine transport system. But to answer your question, yes, there are a number of drugs one could use to saturate specific transport systems. Conversely, there are also a number of drugs which look like brain nutrients and which therefore easily gain access to the brain.

Bray: From what you've been saying, the brain ought to allow the entry of steroids in spite of special binding compounds such as alpha fetoprotein. How does alpha fetoprotein work given that bound compounds still have access to the brain?

Pardridge: This has been studied mainly in the rat. Alpha fetoprotein of the newborn rodent binds estradiol; that of man and fetal calf does not. In terms of our current thinking on the developing rodent brain, it's believed that testosterone enjoys relatively free diffusion into brain but that estradiol, by virtue of the binding properties of alpha fetoprotein, does not. It inhibits estradiol influx by around tenfold but does not abolish estradiol transport into brain. Its binding half time is around $1 \frac{1}{2}$ to 2 seconds, which is slightly longer than transit time through brain capillaries. Others have data on a binding protein peculiar to the pregnant guinea pig. It binds progesterone. Westphal has measured the kinetics of the reactions at $37^{\circ} \mathrm{C}$ and finds a debinding half time of 1.8 seconds. Again brain capillary transit time is around $800 \mathrm{msec}$. Therefore, the approximation of the debinding rate constant and the transit time are what allows transport of protein-bound hormones to take place (Endocrinology (1980) 106: 1137).

Kroc: Would you care to comment on other barriers in the body, such as the retinal barrier?

Pardridge: There is a blood-retinal barrier. The retinal capillary, like the brain capillary, has very tight junctions. Compounds without lipid solubility or specific transport systems cannot therefore pass. Also, analogous to the CVOs of the brain, the leaky choroidal capillaries of the eye enable certain compounds to enter the eye interstitial space. These in turn are kept out of the retina by the tight junction layer of the pigment epithelium, but the latter does have some specific transport systems. Vitamin A gets into the retina when retinol binding protein escapes from prealbumin and passes through the choroidal capillaries. It then reacts with a retinol/vitamin A binding receptor on the pigment epithelium.

In the placenta, there is not a filtration barrier, but rather a diffusion barrier. There's also a blood-testes barrier. Tight junctions in the Sertoli cells keep materials out of the tubules. The permeability factors of the Sertoli cells are very similar to those of the BBB.

Kroc: How does rT3 play a role?

Pardridge: It competes with T3 for its transport sites, but it is probably normally not much of a factor at in vivo concentrations. The $\mathrm{km}$ of the T3 transport system probably evolved more to compete with albumin than to allow for the physiological competition of various thyronines.

Brown: How does anesthesia effect the system you have reviewed?

Pardridge: All of our studies have been done using barbiturate anesthesia. A few studies have compared results in awake and barbiturate anesthetized animals using carotid catheters. In general the findings are the same. The one exception is that the neutral amino acid transport system seems to be accentuated by barbiturates (J. Neurochem. (1979) 33: 963).

Fernstrom: In diabetes, retinal capillaries show degeneration. Is the BBB also degenerated?

Pardridge: There has been some recent work in this area. CSF protein levels are known to be high in the diabetic. It probably is due to a faster influx of protein more than a slower efflux, but it could be due to either. In fact, the CVOs are most likely to be affected. Normally, the fenestrations of CVO capillaries keep out albumin, but this function may be compromised in the diabetic.

\section{Sclafani: How do electrolytic lesions effect the BBB?}

Pardridge: There have been some studies using trypan blue suggesting that the dye leaks into adjacent areas and that the capillaries have become leaky. But if you find that trypan blue does not leak into adjacent areas, you shouldn't exclude the possibility of more selective modification. The trypan blue experiments are relatively crude, however, and should be combined with the Oldendorf technique. 
Steffens: What about peptides that are apparently found in high concentrations in the brain, such as CCK? Are they transported into the brain or are they synthesized there?

Pardridge: I really don't know, but I expect that several upcoming papers will address this issue. In general, studies aimed at answering your question have not been done.

Porte: So how do peptides actually gain access to the brain?

Pardridge: This is obviously a very controversial area. My bias is that peptides follow the same principles as other compounds. Numerous studies have provided negative evidence for the passage of peptides into the brain or for only a very slow passage. So for present, we must conclude that the $\mathrm{BBB}$ is relatively impermeable to them. I would be willing to switch boats as soon as someone demonstrates a specific BBB transport system for a peptide. For now we can say that peptides enter brain only very slowly and probably into the CSF via the leaky capillaries of the choroid plexus and other cros. But you must remember that only around one five thousandth of the total brain capillary surface area is represented by the choroid plexus. This mechanism does exist, however, for the slow diffusion of peptides into the CSF.

Porte: Can you make some comments about 3-o-methyl glucose and other sugars. Are they competitive with glucose for transport into the brain? Are their observed effects due only to this CNS exclusion or are there other metabolic effects? I'm not aware of metabolic effects of 3-o-methylglucose, but perhaps not enough has been given.

Pardridge: Yes, that would make an interesting experiment. The affinity of the transport system is $1 \frac{1}{2}$ times greater for 2-DG than for glucose, whereas the affinity of hexokinase for glucose is $2 \frac{1}{2}$ times what it is for 2-DG. The 2-DG molecule is therefore going to have a greater impact at the transport system. But this doesn't mean that 2-DG can't have a metabolic effect as well.

Porte: So, if you give 2-DG, the CNS gets relatively a lot. This in turn triggers reflexes causing rapid peripheral hyperglycemia and thus probably circumventing a peripheral hypoglycemic effect from ever really occurring. There may normally never be much peripheral effect of 2DG.
Pardridge: Probably, but 2-DG could have the same effect peripherally but it is masked because peripheral tissues, unlike the brain, can recruit alternative carbon sources for fuel.

Nicolaidis: There is actually a very strong peripheral effect of 2-DG. It causes a marked decrease of total oxygen consumption which cannot be attributed soleley to the CNS.

Porte: But how can you be sure that the effect is peripheral? After all, the brain is the major consumer of oxygen at rest.

Nicolaidis: Yes, but the drop is too large to be attributed to the brain only.

Porte: There's no question that if you give 2-DG in very large doses, you can get peripheral effects. All I'm suggesting is that when the drug is normally given, there's a very strong central effect and that this cannot easily be separated from other peripheral actions.

B. Jeanrenaud: Fat cells have decreased ATP when 2-DG is administered, but this has only been assessed in vitro.

Sclafani: One way to determine if there are normally peripheral effects of 2-DG would be to give alpha adrenergic blockers into the CSF. This is reported to block many of 2-DG's central effects, such that peripheral effects could be measured independently.

Porte: How are these eight transport systems regulated? Is their function merely to get nutrients into the brain at a high rate, or are there specific signals involved?

Pardridge: There are many instances of modulation of specific BBB transport systems. For instance, the glucose transport system is enhanced by 'T3. The neutral amino acid system is greatly induced in hepatic encephalopathy, and indeed, that's probably the main reason you see elevated tryptophan and serotonin in the cirrhotic brain. Recall that four carriers are greatly enhanced during the perinatal period. And (basic amino acid, choline, purine base, nucleoside) the ketone-lactate system is activated during fasting or any ketotic state. 